\title{
The Motion Control and Processing Software Design of an On-line Automatic Aluminum Wheel Recognition System
}

\author{
Shuangyong Liu ${ }^{1, a}$, Shaobo Sun ${ }^{2, b}$, Yiyang Zhang *, Yong Han ${ }^{4, d}$ \\ ${ }^{1,4}$ CITIC Dicastal Co., Ltd., Qinhuangdao 066011, China \\ 2, *School of Material Science and Engineering, Beihang University, Beijing 100191, China \\ *email: zhangyiyang@buaa.edu.cn (corresponding author, Yiyang Zhang),
}

Keywords: Aluminum Wheels; Recognition System; Motion Control; Processing Software

\begin{abstract}
This paper presents the motion control and software design of an on-line automatic recognition system for automobile aluminum wheels. The system mainly consists of a recognition station, two laser displacement sensors, a ball-screw, an industrial computer with data processing software, and a programmable logic controller (PLC). The motion control, which incorporates technologies of microelectronic and computer combining the information and intelligence with mechanical devices and power equipments, ensures stability of the wheel recognition system. Each wheel can be identified correctly in less than 20 seconds due to the robust processing software, and the designed action has been achieved accurately. In addition, the man-machine interface is concisely clear and can be easily manipulated and upgraded. The recognition system could meet the requirement of modern wheel manufacturing with a great deal of flexibility.
\end{abstract}

\section{Introduction}

The growth of economy and enhancement of consumption ability in China has help to popularize automobiles, which brings Chinese automobile industry's quite rapid development during the past 20 years [1]. It is well known that, the aluminum wheels are one of the most important automobile parts and their extensive use put forward a higher requirement for quality and quantity.

The typical production processes of the automobile aluminum wheels are metal melting, purification process, low-pressure casting, $\mathrm{X}$ ray radiographic inspection, heat treatment, machining, dynamic balancing detection, leakage test and painting in sequence [2]. After the casting stage, the wheel blanks usually are transferred on a roller bed in random order through a series of process steps. Therefore, each wheel should be identified and classified correctly before each processing step. Fig. 1 shows a typical aluminum wheel.

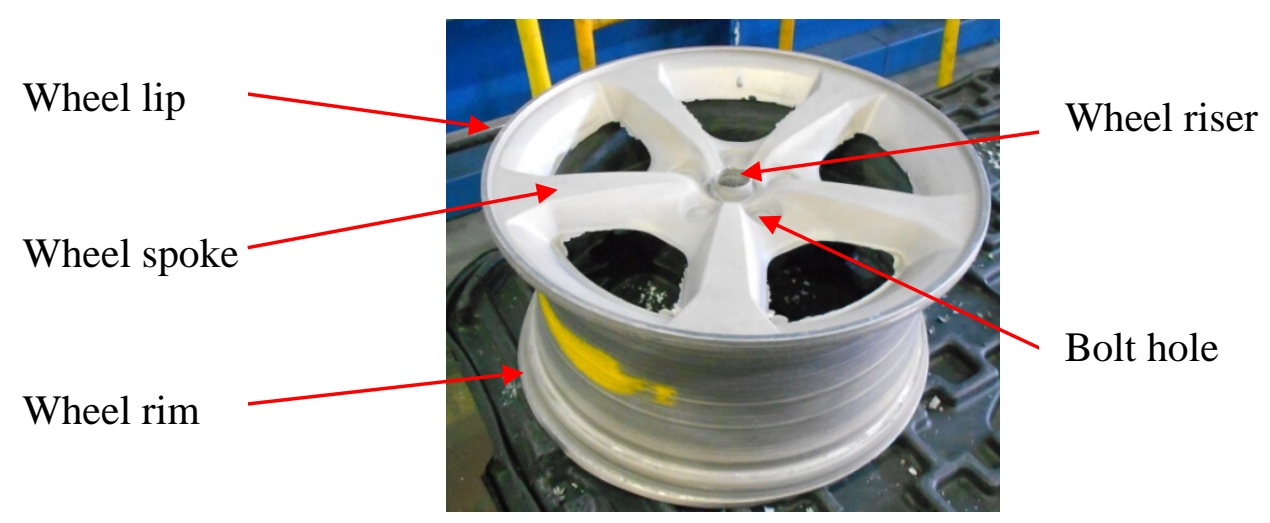

Fig. 1 The typical configuration of the aluminum wheel

Traditionally, the wheel identification is based on operators' observation and practical experience, which could be unreliable, costly and time consuming. It is becoming harder and harder for traditional recognition method to address market requirements. To improve productivity and reduce cost, the development of an on-line aluminum wheel recognition system is necessary. 
This paper aims to propose the motion control and processing software design for the on-line automatic wheel recognition system, which incorporates technologies of microelectronic and computer to combine the information and intelligence with mechanical devices and power equipments.

\section{System design for recognition}

Recognition System Structure. Fig.2 shows the schematic diagram of the automation aluminum wheel recognition system. In this system, a recognition station is used to center, lift and turn the wheel; a roller bed is used to deliver the wheel; two laser displacement sensors are used to scan the wheel; and a ball-screw is used to drive laser displacement sensors with a servo motor.

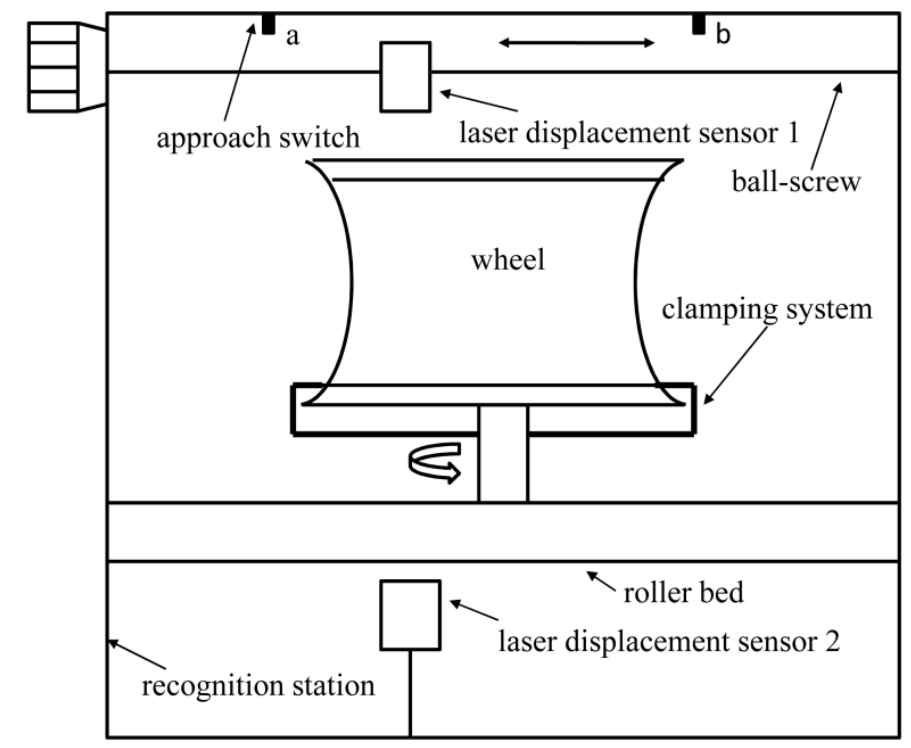

Fig.3 The structure of the wheel recognition system

Mechanical Kinematic Scheme Design. During the recognition process, when a wheel is delivered to the recognition station by the roller bed, a signal is sent to PLC to control the recognition station to clamp the wheel. As the wheel being adjusted centering and lifted, PLC generate a signal to the industrial computer, and then the industrial computer control laser displacement sensor 1 driven by a ball-screw to scan the wheel at a uniform velocity of $250 \mathrm{~mm} / \mathrm{s}$ along the centerline of the wheel from point a to point $b$. As long as laser displacement sensor 1 reaches point $b$, it stops scanning and initiates a signal to PLC which will stop the movement of laser displacement sensor 1 . Then, PLC controls the station to rotate the wheel. Laser displacement sensor 2 then scans the spokes while the wheel is rotated. It is worth noting that the height of laser displacement sensor 2 can be adjusted automatically to meet the measurement of various wheels. When one rotation is finished, the movement of the wheel and laser scanning stops. After the above procedures, the laser displacement sensors and wheel recognition station return to the initial state. The data collected by the two laser displacement sensors are transferred to the industrial computer through universal serial bus (USB) communication. The scanning strategy of the two laser displacement sensors is shown in Fig.3 [3]. 


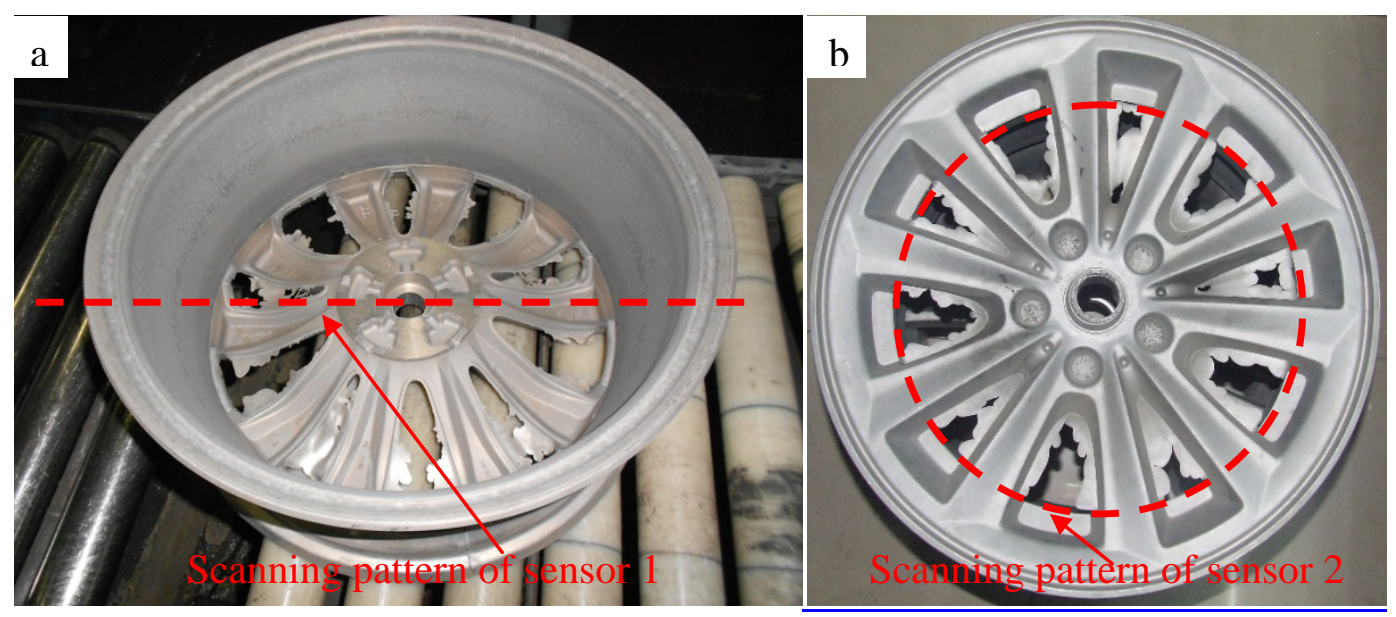

Fig.4 The scanning strategy of the two laser sensors

\section{Motion control strategy}

During the motion control, the instructions made by master system will turn into some desired movement to get a certain position, velocity, and accelerated velocity, according to the proposed solution [4]. As is shown in Fig.4, typical motion control system mainly comprises a motion controller, driving parts, actuating mechanism and feedback equipment.

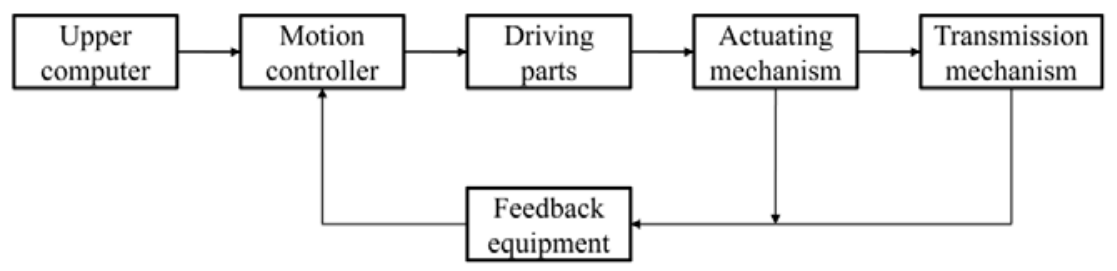

Fig4. Typical motion control system

A programmable logic controller (PLC) is adopted as the motion controller. With the function of motion control, the PLC can interpret a pulse signal or an analog signal and initiate the proper motion program for a given wheel [5]. A PLC's work mode is scan method, which will perform a input and a output only once, in every scan cycle of a program's execution [6].

By using an AC servo motor as the driving parts, enlarged current and simple motion control can be achieved. The rotor of permanent magnet AC servo motor is made of permanent magnet material, which can generate constant magnetic field. When a current is provided toward the stator winding, the force on the stator armature will drive the rotor rotation. Once the rotor rotates, it will continually rotate, while three-phase sinusoidal current toward the stator winding keeps a relative relationship with the pole position of rotor [7].

\section{Processing software design of the system}

System design of the software is shown in Fig.5. This software includes communication task, motion control task, wheel recognition task, and database task.

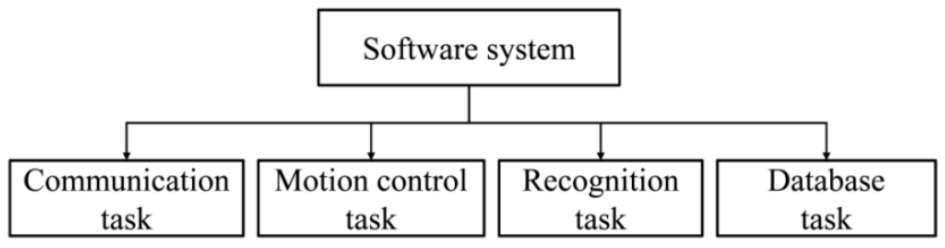

Fig.5 System design of the software 
The Program of PLC. The program of PLC can be called to communicate with the industrial computer and control the motion of the system. When the industrial computer initiates a signal to the PLC, it will interpret the signal and control the movement of mechanical device. In the system, a SYSMAC CP1H PLC is adopted, which takes the central processing unit (CPU) as its principal part. With 24 inputs and 16 outputs, it can calculate the motion and the output pulse signal for 4 axes in a relative high speed. In addition, the communication of RS232 and RS422A/485 can be used.

The Program of VC++. The program established by $\mathrm{VC}++6.0$ is used by the industrial computer to communicate with the PLC, recognize the aluminum wheel types, and read data from a database. Fig. 6 shows the structure of the program of $\mathrm{VC}++$.

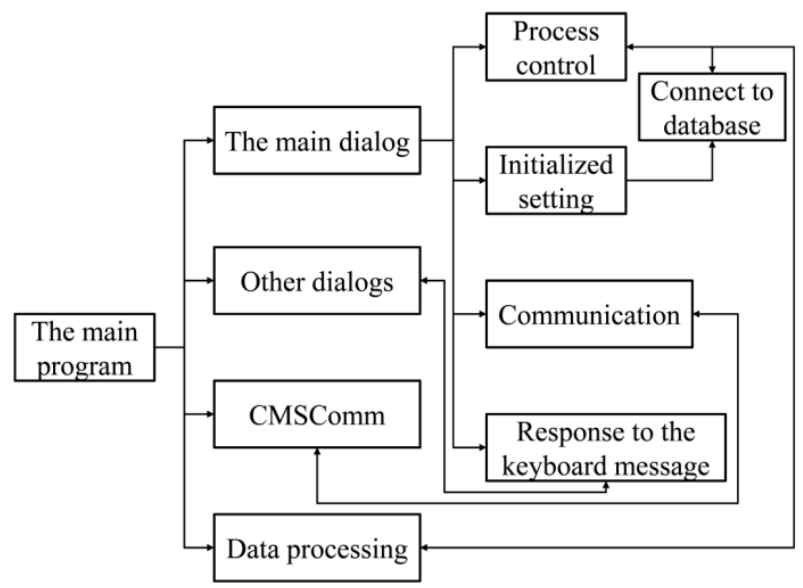

Fig.6 The structure of the program of VC++

The main program consist 4 main modules: the main dialog is used as the main interface of this system; other dialogs are setting for some assistant functions; the class of CMSComm is generated with the control of MSComm for communication with PLC; and data processing is used to calculate the data scanned by the two laser sensors. In addition, 4 main functions that are process control, initialized setting, communication and response to the keyboard message, contribute to the main dialog. For example, during the process control, the identifying information is compared with the information in database for wheel recognition, while the database is connected in initialized setting, and then the results will be sent to the PLC for further movement of mechanical device.

\section{Result}

Ten different types of aluminum wheels were recognized by this system, as listed in Table 1 . 
Table 1 result of 10 wheels identified by the system

\begin{tabular}{|c|c|c|c|c|c|c|c|c|}
\hline \multirow[b]{2}{*}{ Number } & \multicolumn{4}{|c|}{ Identifying information } & \multicolumn{4}{|c|}{ Information in database } \\
\hline & $\begin{array}{l}\text { Wheel } \\
\text { type }\end{array}$ & $\begin{array}{l}\text { Diameter } \\
\text { (mm) }\end{array}$ & $\begin{array}{l}\text { Thickness } \\
\text { (mm) }\end{array}$ & $\begin{array}{c}\text { Number } \\
\text { of } \\
\text { spokes }\end{array}$ & $\begin{array}{l}\text { Wheel } \\
\text { type }\end{array}$ & $\begin{array}{l}\text { Diameter } \\
\text { (mm) }\end{array}$ & $\begin{array}{l}\text { Thickness } \\
\text { (mm) }\end{array}$ & $\begin{array}{c}\text { Number } \\
\text { of } \\
\text { spokes }\end{array}$ \\
\hline 1 & $22 Z 43$ & 451.7 & 210.9 & 10 & $22 Z 43$ & $\begin{array}{c}444.5 \sim \\
469.9 \\
\end{array}$ & $\begin{array}{c}190.5^{\sim} \\
215.9 \\
\end{array}$ & 10 \\
\hline 2 & $22 Z 35$ & 501.6 & 222.3 & 15 & $22 Z 35$ & $\begin{array}{c}495.3 \sim \\
520.7 \\
\end{array}$ & $\begin{array}{c}203.2 \sim \\
228.6 \\
\end{array}$ & 15 \\
\hline 3 & $22 Z 37$ & 449.9 & 212.5 & 15 & $22 Z 37$ & $\begin{array}{c}444.5 \sim \\
469.9 \\
\end{array}$ & $\begin{array}{c}190.5 \sim \\
215.9 \\
\end{array}$ & 15 \\
\hline 4 & $22 Z 37$ & 460.5 & 212.4 & 15 & $22 Z 37$ & $\begin{array}{c}444.5 \sim \\
469.9 \\
\end{array}$ & $\begin{array}{c}190.5 \sim \\
215.9 \\
\end{array}$ & 15 \\
\hline 5 & $22 Z 22$ & 515.5 & 209.1 & 5 & $22 Z 22$ & $\begin{array}{l}495.3 \sim \\
520.7 \\
\end{array}$ & $\begin{array}{c}190.5 \sim \\
215.9 \\
\end{array}$ & 5 \\
\hline 6 & $22 Z 22$ & 508.6 & 203.7 & 5 & $22 Z 22$ & $\begin{array}{c}495.3 \sim \\
520.7\end{array}$ & $\begin{array}{c}190.5^{\sim} \\
215.9\end{array}$ & 5 \\
\hline 7 & $22 Z 35$ & 496.9 & 209.8 & 15 & $22 Z 35$ & $\begin{array}{l}495.3 \sim \\
520.7 \\
\end{array}$ & $\begin{array}{c}203.2 \sim \\
228.6 \\
\end{array}$ & 15 \\
\hline 8 & $22 \mathrm{Z} 43$ & 465.5 & 213.4 & 10 & $22 Z 43$ & $\begin{array}{c}444.5 \sim \\
469.9 \\
\end{array}$ & $\begin{array}{c}190.5 \sim \\
215.9 \\
\end{array}$ & 10 \\
\hline 9 & $22 \mathrm{Z} 22$ & 510.3 & 205.7 & 5 & $22 Z 22$ & $\begin{array}{c}495.3 \sim \\
520.7 \\
\end{array}$ & $\begin{array}{c}190.5 \sim \\
215.9 \\
\end{array}$ & 5 \\
\hline 10 & $22 Z 43$ & 460.9 & 200.2 & 10 & $22 Z 43$ & $\begin{array}{c}444.5 \sim \\
469.9 \\
\end{array}$ & $\begin{array}{c}190.5 \sim \\
215.9 \\
\end{array}$ & 10 \\
\hline
\end{tabular}

According to table 1, ten different types of automobile wheels were recognized by this system, and all of them were identified successfully by this system, with the total time of 20s per wheel. High stability is properly maintained, and the designed action and function has been achieved.

The man-machine interface is used to monitor the processing of wheel recognition in real time, and communicate with operators. Despite the system is complex, the interface is concisely clear that can be easily manipulated. Moreover, it has superiority in system upgrade, that operators can alter the feature data of various types of wheels in the database conveniently.

\section{Conclusion}

This paper proposes the motion control and processing software design of an on-line automatic aluminum wheel recognition system. A recognition station, two laser displacement sensors, a ballscrew, an industrial computer with data processing software, and a programmable logic controller (PLC) compose the system. Experiment results show that the system can identify various types of wheels correctly with the total time of 20s per wheel, and excellent stability has been obtained. This motion control system and the robust software make the recognition exhibit much better repeatability and reliability compared to the manual performance. In the actual production of aluminum wheel, this system could meet the requirement of modern wheel manufacturing with a great deal of flexibility.

\section{Acknowledgements}

The authors wish to acknowledge the financially support by the National High Technology Research and Development Program of China under the Contract of 2013AA031002.

\section{References}

[1] Shiying Chen: National Income and Popularizing of Chinese automobiles, Chinese market, Vol. 13(2010), p. 72-75. 
[2] Ping Li, Danjian Chen, Zhutang Wang: Production and Performance of Aluminum Alloy Wheel, Light alloy fabrication technology, Vol. 39(2011), p. 1-20.

[3] Yiyang Zhang: An On-line Automatic Aluminum Wheel Recognition System, submitted to ICCSET2015, Jinan (2015).

[4] Lifeng Yan: Research on Motion Controlling Technology, submitted to Sichuan University, Chengdu (2001).

[5] Jinheng Han: Research on High Accuracy Servo System Based on Motion Control Card, submitted to Qingdao University, Qingdao (2009).

[6] Yukang Tian: Research on Interpretation Method for PLC Programming Language and System Implementation, submitted to Wuhan University of Technology, Wuhan (2004).

[7] Jiatao Liao: Research on Filament Winding Tension Controlling Based on AC Servo Motor, submitted to Wuhan University of Technology, Wuhan (2011). 